ren deutscher Anlagen angesichts der hier bestehenden Sicherheitsstandards für unzulässig. Dies gelte auch für Wackersdorf.

Insgesamt stellt der Tagungsbericht einen materialreichen, die Probleme grenzüberschreitender Rechtsfragen be Kernanlagen gut aufbereitenden Sammelband dar, der die augenblickliche Diskussion bereichern kann.

Michael Kilian

\title{
Herbert Baumgartner
}

Staat, Bürokratie und blockierte Entwicklung. Die Planung in Mexiko.

Peter Lang: Frankfurt a. M./Bern/New-York, 1987 (Europäische Hochschulschriften, Reihe XXXI: Politikwissenschaft, Band 101), 303 S., SFR 65,-

Die zentrale Bedeutung von staatlicher Planung für die wirtschaftlich-soziale Entwicklung der Länder der Dritten Welt liegt auf der Hand, die Ineffizienz und Kontraproduktivität einer ausufernden und sich selbst bedienenden Bürokratie als Gefahr für vor allem junge Staaten ist ebenso bekannt. Erfolge von zukunftsweisender Planung werden daher in erster Linie in solchen Staaten erwartet, die wie Mexiko über eine ausgebaute Industrie, ausreichende Ressourcen und ein politisch stabiles System verfügen und von daher zu dem Bereich der sog. Schwellenländer gerechnet werden können.

Baumgartner, den Lesern dieser Zeitschrift mit einem Beitrag zur ökonomischen Krise Mexikos bekannt - VRU 1984, S. 213 ff. -, beschreibt auf der Grundlage umfangreichen Materials - das Literaturverzeichnis erstreckt sich auf 45 Seiten - und Feldstudien vor Ort 1983/84 die Planung in Mexiko, so der zutreffende Untertitel, der einer verbreiteten Unsitte nach erst sagt, worum es bei der Arbeit geht. Gab es auch schon seit den 30er Jahren (Planungsgesetz von 1930 im Gefolge der Weltwirtschaftskrise 1929) Ansätze zu einer staatlichen Wirtschaftsplanung und in der Secretería de Presidencia neben dem den laufenden Haushalt festsetzenden Finanzministerium eine gewisse administrative Organisation für Planung, so versuchte doch erst Echeverría (1970-1976) die Koordination der diversen Planungsgremien voranzubringen, indes mit geringem Erfolg in der Sache, dafür aber mit einer Aufblähung der Bürokratie. Präsident López Portillo (1976-1982), ehemaliger Finanzminister, sah die Notwendigkeit einer zentralen politischen Stelle für Planung, die Secretería de Programmación y Presupuesto, das Planungs- und Haushaltsministerium, wurde geschaffen. Planungsminister wurde Miguel de la Madrid, der 1982, und damit zeigte sich die politische Bedeutung des Planungsministeriums, zum Präsidenten gewählt wurde. Gleich zu Beginn seiner Amtszeit erhielt die staatliche Planung Verfassungsrang, Art. 25 und 26. Den Aufstieg de la Madrids und seiner Mannschaft schildert B. minutiös, S. 205-209. Ein Generationswechsel in der politischen Szene Mexikos war eingeleitet und wird heute abgeschlossen mit der Nachfol- 
ge des erst vierzigjährigen Carlos Salinas de Gortari, der, ebenfalls Planungsminister, nunmehr auch im Amt des Staatspräsidenten Nachfolger de la Madrids ist.

Ob und inwieweit sich makroökonomische Planung in der Krise (Olpreisverfall, Kapitalflucht, Auslandsverschuldung) bewährt, kann eindeutig nicht beantwortet werden. B. zeigt allerdings S. 85 ff. Kritikpunkte etwa bei dem Industrieplan und dem Globalen Entwicklungsplan, beide 1980-1982, auf in der Vernachlässigung grundlegender Strukturveränderungen hinsichtlich Einkommensverteilung und unterschiedlicher Produktivität.

Diese von Elsenhans betreute Konstanzer Dissertation vermag in der Tat umfassend die Bedingungen und Ergebnisse staatlicher Planung in einem auf Wirtschaftswachstum ausgerichteten Staat der Dritten Welt aufzuzeigen. Die etwas bemüht wirkende und fruchtlose Auseinandersetzung mit marxistischen und modernisierungstheoretischen Uberlegungen zur Rolle des Staates in einem Entwicklungsland, nur um noch eine neue Begriffsbildung der Staatsklasse abzusichern, sollte mit Nachsicht gelesen werden.

Gerhard Scheffler

\section{Niels-Jürgen Seeberg-Elverfeldt}

\section{Die Streitbeilegung im Tiefseebergbaurecht}

Die Probleme nach der Seerechtskonvention unter besonderer Berücksichtigung des Rechtsschutzes Privater

Nomos Verlagsgesellschaft, Baden-Baden, 1986, 185 S., DM 47,-

Neben der Internationalisierung des Meeresbodens außerhalb der Grenzen küstenstaatlicher Jurisdiktion ist kennzeichnend für das durch die Seerechtskonvention 1982 errichtete Tiefseebodenregime die Vielzahl der auftretenden Rechtsbeziehungen - und damit der möglichen Streitverhältnisse -, die auch aus der geplanten Errichtung der Internationalen Meeresboden-Behörde sowie eines behördeneigenen Unternehmens resultiert.

Nachteilig, was die Klarheit und Ubersichtlichkeit des die Beilegung von Meeresbodenstreitigkeiten regelnden Normengeflechts betrifft, hat sich zudem ausgewirkt, daß diese Materie auf der Konferenz zunächst separat behandelt und erst während der 6. Session in das allgemeine System integriert wurde. Der offenkundige Verdienst der Untersuchung Seeberg-Elverfeldts besteht hier darin, Zusammenhang und Systematik der vertraglichen Grundlagen für die Streitbeilegung im Tiefseebergbaurecht herausgearbeitet zu haben.

Der für die Praxis bedeutsame Aspekt der Darstellung wird nicht dadurch relativiert, daß praktische Fälle auch nach der (realistischen) Einschätzung des Verfassers in absehbarer Zeit nicht zu erwarten sind. Da sich Seeberg-Elverfeldt besonders mit dem Rechtsschutz Privater auseinander setzt, bietet er gerade denjenigen, die zu einem wesentlichen Teil an Bergbauaktivitäten beteiligt sein werden, eine wichtige Entscheidungshilfe be- 